This item was submitted to Loughborough's Research Repository by the author.

Items in Figshare are protected by copyright, with all rights reserved, unless otherwise indicated.

\title{
3D body scanning in the apparel industry: Do we really know where we are heading?
}

PLEASE CITE THE PUBLISHED VERSION

https://www.3dbody.tech/cap/papers2019.html

\section{PUBLISHER}

Hometrica Consulting

VERSION

AM (Accepted Manuscript)

\section{PUBLISHER STATEMENT}

Reproduction of the proceedings or any parts thereof (excluding short quotations for the use in the preparation of reviews and technical and scientific papers) may be made only after obtaining the specific approval of the publisher. The papers appearing in the proceedings reflect the author's opinions. Their inclusion in these publications does not necessary constitute endorsement by the editor or by the publisher. Authors retain all rights to individual papers.

\section{LICENCE}

CC BY-NC-ND 4.0

\section{REPOSITORY RECORD}

Januszkiewicz, Monika, Christopher J. Parker, Steven G Hayes, and Simeon Gill. 2019. "3D Body Scanning in the Apparel Industry: Do We Really Know Where We Are Heading?". figshare.

https://hdl.handle.net/2134/9817118.v1. 


\title{
3D Body Scanning in the Apparel Industry: Do we really know where we are heading?
}

\author{
Monika Januszkiewicz ${ }^{1}$, Christopher J. Parker ${ }^{2}$, Steven G, Hayes ${ }^{1}$, Simeon Gill ${ }^{1}$. \\ ${ }^{1}$ The University of Manchester, Oxford Road, Manchester, M13 9PL \\ ${ }^{2}$ Loughborough University, Epinal Way, Loughborough, LE11 3TU \\ 1Monika.Januszkiewicz@manchester.ac.uk
}

Paper ID: \#43

\begin{abstract}
This paper through - the Diffusion of Innovation Model - shows that while 3D Body Scanning brings some refining and improvements of existing methods, it does not introduce new concepts that depart from traditional retail practices. 3D Body Scanning is - potentially - a powerful way of approaching size and fit in apparel and one that presents novel opportunities. Yet, despite the advantages that this technology offers, and the many initiatives that have taken place, 3D Body Scanning has not reached its full potential and has failed to produce the expected results held by many stakeholders. Stakeholders must increase collaboration to realise 3D Body Scanning's relative advantage. Much of the potential has, however, been promoted by distinct organisations that are biases about how the diverse processes and structures will work together, whilst focussing on profit from their own incremental IP. In this paper we elicit 3D Body Scanning's fundamental concepts, and its central goal to provide 'glue' needed to create an innovation. We offer further implications for researchers and policymakers about expecting and managing trends in technology.
\end{abstract}

Keywords: 3D Body Scanning, Open Innovation, Diffusion of Innovation, Stakeholders Analysis, Technology Management.

\section{Introduction}

The technique of applying 3D Body Scanning to fashion retail, both in-store and Electronic Commerce (e-Commerce), has been classified as 'promising' for over the past 30 years [1]. Yet 3D Body Scanning's promise has yet to be realised in the marketplace.

This paper investigates how 3D Body Scanning's stakeholders increase innovation's acceptance (diffusion) to retailers, technology creators, and consumers. In addressing this question, we draw on diffusion of innovation theory, a framework proven to 
increase innovation acceptance in a wide range of technological fields [2]-[4]. We define an innovation as an idea, practice, or object that an individual - or other unit of adoption - perceives as new. An innovation's rate of adoption are described by relative advantage, compatibility, trialability, observable advantage, and [low] complexity. Innovations individuals perceive as excelling in these five characteristics will be adopted more than other innovations [5].

In 3D Body Scanning, innovations are new ideas that require a change in how fashion products are developed. A change in how products are developed is needed to design clothing with a 'good fit'. We define 'good fit' as the garment's drape that conceals the wearer's figure faults, compliment their body, and balances their proportions [6]. Fashion retailers are, however, dissatisfied with 3D Body Scanning because tools to engage in the process of virtual prototyping of the garment on individual body are not yet provided. Consumer's rewards for the retailer's adoption of 3D Body Scanning are, moreover, relatively intangible, often delayed in time, and may not be available for the majority of fashion retailers. 3D Body Scanning innovations have, thus, low relative advantage compared to traditional models [7]. Past research shows that perceived relative advantage is the most important predictor of the rate of adoption of innovations [8]-[10]. Increasing perceived relative advantage of 3D Body Scanning technologies can increase their rate of adoption.

3D Body Scanning's vital stakeholders are technology manufacturers [11], fashion experts [12], academic researchers [14], [15], and software developers [15]. Yet, present stakeholder's disagreements causes imbalanced solutions from the fragmented processes. The steps for technology - retail integration - are treated as distinct from the whole problem and separate from the user's experience. 3D Body Scanning provides a large space of personal, industry specific, and economic assumptions that if unexamined - can be propagated through technology design. Such fragmentation constrains 3D Body Scanning's diffusion. 3D Body Scanning developers must, therefore, see beyond the accepted assumptions and experiences to their design roots [17].

In this paper, we aim to identify how 3D Body Scanning's stakeholders impact relative advantage for fashion retail diffusion. In addressing this aim, we examine how 3D Body Scanning's stakeholders perceive the technology's relative advantage over alternative measurement methods. We interview 39 3D Body Scanning stakeholders from manufacturing, fashion, academia, and software development fields. Focusing on relative advantage, we reveal the actions 3D Body Scanning stakeholders should take to increase fashion retailer's the acceptance of their innovations. We hope, in turn, our work will contribute to 3D Body Scanning's diffusion amongst society. 


\section{Theoretical Background}

Relative advantage is the degree to which an innovation is perceived as being better than the idea it supersedes. Relative advantage is the best predictor of adoption/ usage [17]-[19]. If a customer perceives the innovation as advantageous, the innovation's actual advantage becomes less important.

The nature of the innovation determines adoption's rate and pattern [20]. 3D Body Scanning operates in closed traditional model, forcing stakeholders to develop, build, market, distribute, and support technology on their own. This closed model conceals firms to be self-reliant, encouraging internal research, development, and innovation [21]. While this insula model is - historically - beneficial, the current innovation landscape has changed [20]. As van de Vrande et al. [21] establishes, the greater labour mobility, abundant venture capital, and widely dispersed knowledge makes internal innovate too expensive. To achieve a relative advantage, firms must, therefore, draw on both external and internal ideas and paths to the market.

Open innovation has been proposed by Chesbrough [22] as a new paradigm of innovation management. Chesbrough (ibid) defines open innovation as "the use of purposive knowledge inflows and outflows to accelerate internal innovation process". At the heart of the open paradigm is the assumption that organisations cannot conduct all innovation activities by themselves. Instead, organisations must capitalise on external knowledge [23]. In contrast to closed innovation, open innovation processes are characterised as spanning firm boundaries [24].

\section{Methodology}

To analyse 3D Body Scanning's trends, motives and management challenges, we recruited stakeholders through purposive sampling. To identify trends, we only selected stakeholders with long tenure and represent organisations that innovate.

First, respondents indicated if they have addressed research, diffusion, dissemination, or implementation of technology in the fashion sector. Second, respondents had to be employed in a 3D Body Scanning retail or retail technology job for at least five years. We stratified our sample across two size classes (10-99 employees, and 100-499 employees): as used by van de Vrande et al. [21]. We sampled company employee's innovation responsibilities; including business owners, managers, R\&D managers, or staff managing new business development activities.

We collected 30 semi-structured interviews with 39 individuals through face-to-face and online via the respondent's firm's internal-communication software. We organised interviews in a semi-structured format, with the open-ended questions to give stakeholders the latitude to articulate their responses [25]. We transcribed all interviews verbatim and reveal underlying themes through thematic analysis. 


\section{Results and Analysis}

\subsection{Rich Picture}

Figure 1 shows fashion experts are primary users and - to a large extent - drive the use of 3D Body Scanning information in practice. Their input is important for understanding customer sizing and fit needs and concerns for practical information in product development. Retailers can serve as champions who both promote shared vision and address customer resistance to change. The retail sector therefore plays the crucial role as the link between stakeholders in the supply chain system, yet their channels of communication are very narrow and constrained, as presented in Figure 1.

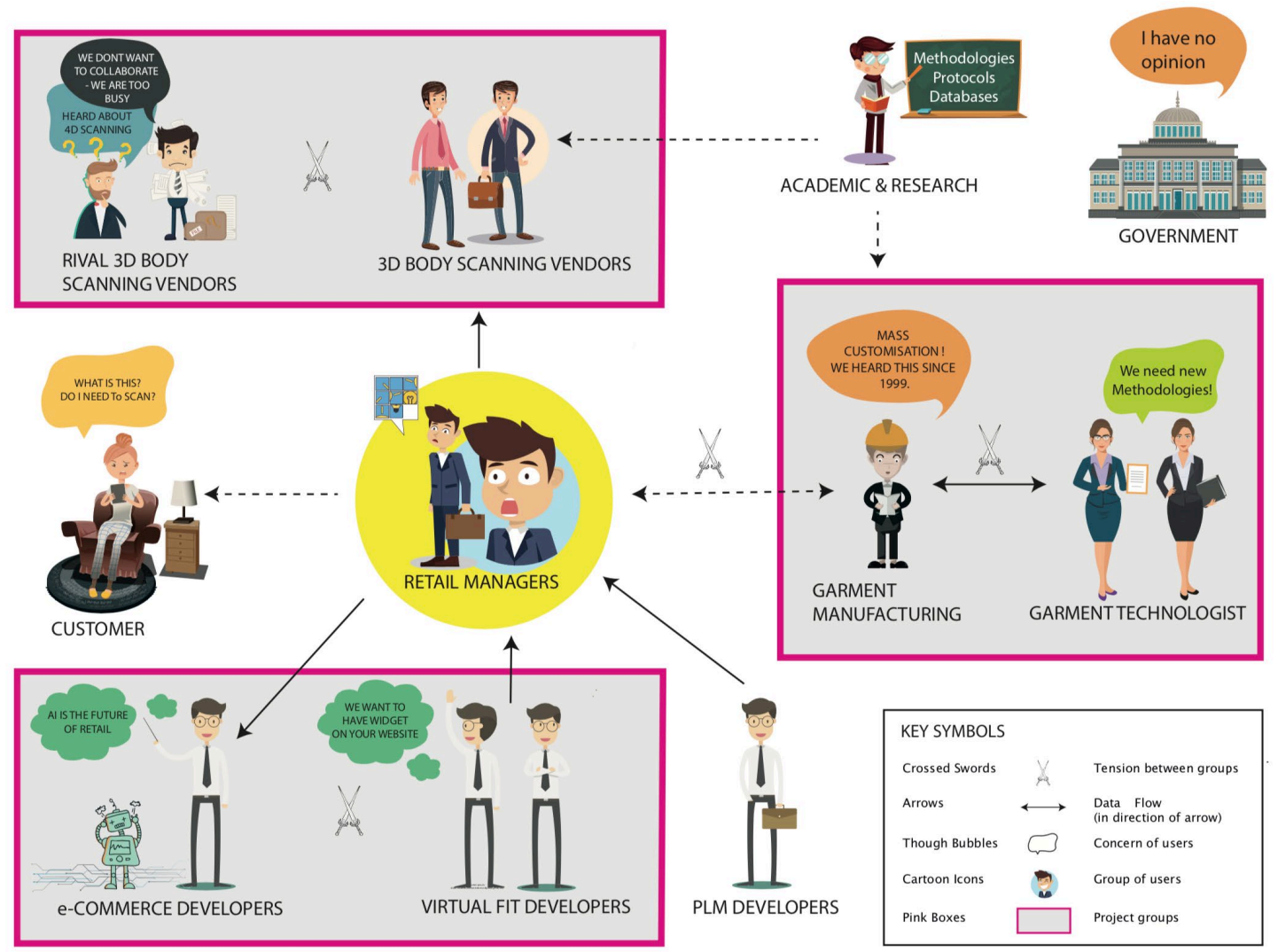

Figure 1 3D Body Scanning Industry Rich Picture

Retail managers are the central stakeholders in rich picture; their main channels of communication are with 3D Body Scanning vendors and e-Commerce developers, yet the flow on communication is unilateral. The conflict between retail managers and garment manufacturers was identified, as these project groups often cannot agree on apparel methodology e.g. landmark placement, pattern theories and grading principles. Retail managers also communicate with consumer, but their communication ties are latent. The consumer does not return feedback data to any of the stakeholders.

Within development groups the data flow is scattered. Virtual fit developers do not communicate directly with e-Commerce developers, but through retail managers. 
However, retail managers often lack technical knowledge and due to the gaps in knowledge may be sceptical about new developments. Furthermore, PLM developer's position is not yet significant in communication. However, this project group input can be helpful in developing applications that will allow utilization of avatars in computer environments. Moreover, there is no information flow between software developers group and research academic group. Academic researchers communicate with 3D Body Scanning vendors and garment manufacturers on one-sided basis. This project group has the potential to generate standards and guidelines that can facilitate implementation as well as improve the quality and efficiency of technology.

\subsection{Relative Advantage Themes}

Table 1 compares trends towards relative advantage between different industry sectors. The key technology relative advantages are growth and leadership. For ease of presentation, frequency of responses from thematic analysis has been averaged.

Table 1: Perceived trends in relative advantage practices between industries

\begin{tabular}{l|llll}
\hline $\begin{array}{l}\text { Relative Advantage } \\
\text { theme }\end{array}$ & $\begin{array}{l}\text { Apparel } \\
(\mathbf{n = 1 3})\end{array}$ & $\begin{array}{l}\text { Software } \\
(\mathbf{n = 1 3 )}\end{array}$ & $\begin{array}{l}\text { Hardware } \\
(\mathbf{n = 8})\end{array}$ & $\begin{array}{l}\text { Research } \\
(\mathbf{n = 5})\end{array}$ \\
\hline Economic Growth & 0.85 & 0.77 & 2.38 & 0.40 \\
Leadership Status & 0.46 & 0.69 & 0.25 & 0.20 \\
\hline
\end{tabular}

Note 1: Average score with increase coded 1 , stable coded 0 and decrease coded -1 .

\subsubsection{Economic Growth}

Technology stakeholders are individuals that shape 3D Body Scanning design by determining what and how information's would be collected. As Figure 1 highlights, technology stakeholders work independently when defining landmarks requirement, pattern rules, and interactions with other processes. An efficient feedback loop to establish effective innovation diffusion with other stakeholder is, therefore, elusive. In 3D Body Scanning's hardware sector (87\%) the growth was defined by technology exploitation - buying or using intellectual property - including (24\%) patents, (51\%) copyrights, or $(12 \%)$ trademarks to engage in inward IP licensing.

Software developers are classified as e-Commerce developers, Virtual Fit developers and Product Lifecycle managers. Despite both the diversity of knowledge and expertise that this stakeholder collaboration could bring into 3D Body Scanning developments, developers continue to be sited using more traditional, less collaborative methods. One reason stated by $31 \%$ of Virtual Fit developers and $53 \%$ of PLM managers for such hesitancy is that being open about goals and developments provide an important opportunity for competing software developers to challenge their ability and connect with one another to form opposition groups. Interestingly, software group (85\%) favoured growth on technology exploration: venturing 
activities: (42\%) R\&D outsourcing by buying 3D Body Scanners for market research and to build internal scan databases for further analysis and, (18\%) external networking and (25\%) participation with retailers to understand user behaviour.

The technical factors including performance, speed, reliability, and amount of available data were the highest 3D Body Scanning attributes of relative advantage over traditional measurement methods. With a strong focus on efficiency, software and hardware developers still, however, replicate the same old practices for product development. The interviews found that for $91 \%$ of hardware the major reason for this direction is to remain competitive with current retail model.

There is a trend towards increased adoption of open innovation. The apparel sector is, however, left behind. While all the developments came from hardware manufacturers and software firms - in apparel sector technological growth was only favoured by $38 \%$. This sector was less time pressured and had lower emotional involvement for growth. This revealed that this group of stakeholders still plays a minor role in supporting the diffusion process.

Technology stakeholders, however, agree that apparel's transition to 3D needs large investments (28\%), standardisation (53\%), and machine learning algorithms (10\%). However, $63 \%$ of hardware and $85 \%$ of software group members agreed, that 'generic' requirements from apparel clients limits growth.

Retail and Technology stakeholders, therefore, have communication problems. Overcoming these problems requires clearer task and responsibilities divisions, and to balance relationships between organisations. Each stakeholder group's jargon and terminology is often misinterpreted. Research stakeholders, therefore, advocate for close cooperation between academics and consultants, acting as a mediator between firms to create as a common language and promote dialogue.

More collaborative forms of engagement require stakeholders to devolve authority, control, and power over other groups of decision-making stakeholders. This study found that $76 \%$ of stakeholders are often loath to do such devolution. By closer collaboration with academics, manufacturers, and garment technologist, technology developers could create feedback to generate standards and guidelines that can facilitate implementation. They may also improve 3D Body Scanning's quality and efficiency.

\subsubsection{Leadership Status}

The leadership role was highly visible in (38\%) apparel and (24\%) software, and within firms that are bound to abide by a formal hierarchical ranking structure. These stakeholder groups perceive establishing leader position as important to exploit 3D Body Scanning's economic benefits and influence standards creation. Stakeholder from apparel exemplifies this view; that a coalition to build a set of standards was not yet powerful to steer clear vision. 
$17 \%$ of stakeholders spoke against leadership role and its unnecessary hype. They believe the '3D' prefix is overused, with developers being deluded about fantastic applications for often-immediate future. Technology developers marketing language and the absence of workable solutions dominate the market. 3D Body scanning language was described as being dominated by great promises that the technology cannot yet deliver. This resulted in leadership status promising credibility in stretching mythical improvements in existing applications. This view causes a lack of new infrastructure and additional layers in present already very complex fashion ecosystem.

\section{Discussion}

Looking at drivers of relative advantage for long-term success, we find that profitability and status is key for the diffusion. We demonstrate that relative advantage has limited visibility among all the stakeholders. The fashion sector in particular has the lowest visibility. Close engagement with key stakeholders, turning them from passive receivers to active co-creators, is key in diffusion context. Vargo [26] suggest, in a service-dominant marketing logic context, a model of contemporary marketing based on brand value co-creation, where all stakeholders and the firm are resource integrators and co-create a brand's value.

This paper emphasised how stakeholders believe current apparel processes and models are a major factor that restricts innovation. Retail stakeholders complain about 3D Body Scannings' centralised system design. Centralising design often removes retail stakeholders from decision-making, and privilege expert technical knowledge where little knowledge is shared with retailers [27]. Within retail sector only sporadic data on scanner technical factors is available. Thus, retail stakeholders often lose broader perspective on needs for garment development when a narrow-minded view on values related only to technical knowledge in retail diffusion is applied.

Christensen and Bower [28] identifies the root of the tension in disruptive innovation as the conflict between the model already established for the existing technology and that required to exploit the emerging technology. Successful model creates a heuristic logic that connects technical potential with the realisation of economic value [29]. At this early diffusion stage, it is not clear what eventual new model will turn out to be, thus organisations need to develop new capabilities by research and experimentation [30]. This can help to identify and create data needed to justify decisions [31]. To achieve this progress depends on defining the problems being faced and having the right tools to address them [32]. Standards and approaches are essential for full realisation of relative advantage. They form a basis for common-and precise-language for addressing diffusion and deployment of a new technology in retail. And they enable the generalisation of valid - and validated - data that can underpin evidence informed decisions. Thus, industry standardisation would mean commonality in data collection and application e.g. landmark placement, methods, interface and product 
specifications [14], [33] with a common level of precision, accuracy and metadata context likewise [34].

\section{Conclusion}

In this paper, we set out to identify the stakeholders of 3D Body Scanning and their impact on relative advantage for retail diffusion. We identify key stakeholders in 3D Body Scanning innovation as: fashion retailers, apparel manufacturers, 3D Body Scanner producers, e-Commerce software developers, virtual fit developers, academic researchers, PLM managers, and garment technologist. The inter-relationships, influence, and conflict between these stakeholders is visualised through our Rich Picture.

Our key outcome is 3D Body Scanning's stakeholder must improve their cooperation, collaboration, and communication. The result of these improvements is each stakeholder having a clear business case and motivation for taking part. The paper has shown that the adoption rate and impact of 3D Body Scanning depends upon the motivation of the stakeholders who directly benefit from innovation. Retailers by communicating directly with customers, have the biggest power to have impact on the technology diffusion. To increase the relative advantage, 3D Body Scanning vendors need to identify retail needs, triggers and enablers for successful innovation. Moreover, 3D Body Scanning vendors need to establish channels of communication with other stakeholders for applicability (academics and manufacturers), validity (eCommerce developers and garment technologist) and visibility (virtual fit developers and PLM developers). The results of the rich picture analysis provide the basis to refine the general context for 3D Body Scanning advancements like the need for standardisation or building interoperability between applications. This enables to derive more detailed requirements for 3D Body Scanning diffusion in retail.

Our results have implications for technology developers, fashion experts, policy makers, and academic researchers. Our recommendations will improve how evidence is communicated between industries, and the evidence's influence in decision-making processes. This collaborative perspective should also clarify the chasm between fashion experts and technology developers, identify key challenges.

The limitations are the relatively small sample size. This concern could be addressed in future work by surveying a broader range of experts across disciplines of computer science, engineering, fashion and research. Future research should also focus more detailed studies on customer perspective of the service and information provision should be taken to shed more light on early adopters of the system and opinions about propositions put forward in this paper. 


\section{References}

[1] P. R. M. Jones, G. M. West, D. H. Harris, and J. B. Read, "The loughborough anthropometric shadow scanner (LASS)," Endeavour, vol. 13, no. 4, pp. 162$168,1989$.

[2] G. O. Collantes, "Incorporating stakeholders' perspectives into models of new technology diffusion: The case of fuel-cell vehicles," Technol. Forecast. Soc. Change, vol. 74, no. 3, pp. 267-280, 2007.

[3] T. Nokelainen and O. Dedehayir, "Technological adoption and use after mass market displacement: The case of the LP record," Technovation, vol. 36, pp. 65-76, 2015.

[4] Y. J. Masuda et al., "Innovation diffusion within large environmental NGOs through informal network agents," Nat. Sustain., vol. 1, pp. 190-197, 2018.

[5] G. C. Moore, "Integrating Diffusion of Innovations and Theory of Reasoned Action models to predict utilization of information technology by end-users.," in Diffusion and Adoption of Information Technology. IFIP - The International Federation for Information Processing, K. K. and P.-H. J., Eds. Boston, MA, USA: Springer, 1996, pp. 132-146.

[6] D. Tyler, A. Mitchell, and S. Gill, Recent advances in garment manufacturing technology: Joining techniques, 3D body scanning and garment design. Woodhead Publishing Limited, 2012.

[7] S. K. Panigrahi, F. W. Kar, T. A. Fen, L. K. Hoe, and M. Wong, "A Strategic Initiative for Successful Reverse Logistics Management in Retail Industry," Glob. Bus. Rev., vol. 19, no. 3_suppl, pp. S151-S175, 2018.

[8] R. R. Hernandez et al., "Techno-ecological synergies of solar energy for global sustainability,” Nat. Sustain., vol. 2, no. 7, pp. 560-568, 2019.

[9] Everett M Rogers, "Diffusion of preventive innovations," Addict. Behav., vol. Volume 27, no. 6, pp. 989-993, 2002.

[10] L. G. Tornatzky and K. J. Klein, "Innovation Characteristics and Innovation Adoption- Implementation: A Meta-Analysis of Findings," IEEE Trans. Eng. Manag., vol. EM 29, no. 1, pp. 28-45, 1982.

[11] H. A. M. Daanen and F. B. Ter Haar, "3D whole body scanners revisited," Displays, vol. 34, no. 4. pp. 270-275, Oct-2013.

[12] E. Scott and A. S. M. Sayem, "Landmarking and Measuring for Critical Body Shape Analysis Targeting Garment Fit," Proc. 3DBODY.TECH 2018 - 9th Int. Conf. Exhib. 3D Body Scanning Process. Technol. Lugano, Switzerland, 16-17 Oct. 2018, pp. 222-235, 2018.

[13] S. Gill, Y. Wang, M. Ahmed, S. G. Hayes, A. R. G. Harwood, and J. Gill, "Scan to Pattern: How body scanning can help transform traditional methods of creating pattern blocks," in 9th international conference in $3 D$ Body scanning, 2018, pp. 1-5. 
[14] C. J. Parker, S. Gill, and S. G. Hayes, "3D Body Scanning has Suitable Reliability: An Anthropometric Investigation for Garment Construction," in Proceedings of 3DBODY.TECH 2017 - 8th International Conference and Exhibition on 3D Body Scanning and Processing Technologiess, 2017, pp. 298-305.

[15] S. Xia, A. West, C. Istook, and J. Li, “Acquiring Accurate Body Measurements on a Smartphone from Supplied Colored Garments for Online Apparel Purchasing Platforms and E-Retailers," Proc. 3DBODY.TECH 2018 - 9th Int. Conf. Exhib. 3D Body Scanning Process. Technol. Lugano, Switzerland, 16-17 Oct. 2018, pp. 126-130, 2018.

[16] G. Bell, M. Blythe, and P. Sengers, "Making by making strange," ACM Trans. Comput. Interact., vol. 12, no. 2, pp. 149-173, 2005.

[17] E. M. Rogers, Diffusion of Innovations, 5th ed. London, UK: Free Press. A Division of Simon \& Schuster, Inc., 2003.

[18] K. J. Klein and J. S. Sorra, "The challenge of innovation implementation," Acad. Manag. Rev., vol. 21, no. 4, pp. 1055-1080, 1996.

[19] G. C. Moore and I. Benbasat, "Development of an Instrument to Measure the Perceptions of Adopting an Information Technology Innovation," Inf. Syst. Res., vol. 2, no. 3, pp. 192-222, Sep. 1991.

[20] J. D. Linton, "Open innovation/integration versus disintermediation/ disintegration," Technovation, vol. 78, no. June, pp. 1-3, 2018.

[21] V. van de Vrande, J. P. J. de Jong, W. Vanhaverbeke, and M. de Rochemont, "Open innovation in SMEs: Trends, motives and management challenges," Technovation, vol. 29, no. 6-7, pp. 423-437, 2009.

[22] H. Chesbrough and J. Vanhaverbeke, W., West, Open Innovation: Researching a New Paradigm. London: Oxford University Press, 2006.

[23] M. Caetano and D. C. Amaral, "Roadmapping for technology push and partnership: A contribution for open innovation environments," Technovation, vol. 31, no. 7, pp. 320-335, 2011.

[24] J. Henkel, "Selective revealing in open innovation processes: The case of embedded Linux," Res. Policy, vol. 35, no. 7, pp. 953-969, 2006.

[25] M. S. Reed et al., "Who's in and why? A typology of stakeholder analysis methods for natural resource management," J. Environ. Manage., vol. 90, no. 5, pp. 1933-1949, 2009.

[26] S. L. Vargo and R. F. Lusch, "Industrial Marketing Management It 's all B2B ... and beyond: Toward a systems perspective of the market," Ind. Mark. Manag., vol. 40, no. 2, pp. 181-187, 2011.

[27] F. Caro and V. Martinez-de-Albeniz, "Fast Fashion: Business Model Overview and Research Opportunities," in Retail Supply Chain ManagementQuantitative Models and Empirical Studies, Second., N. Agrawal and S. A. Smith, Eds. Springer, 2015, p. 454. 
[28] C. M. Christensen and J. L. Bower, "Customer Power, Strategic Investment, and the Failure of Leading Firms," Strateg. Manag. J., vol. 17, no. 3, pp. 197218, 1996.

[29] H. Chesbrough and R. S. Rosenbloom, "The role of the business model in capturing value from innovation: Evidence from Xerox Corporation's technology spin-off companies," Ind. Corp. Chang., vol. 11, no. 3, pp. 529$555,2002$.

[30] R. A. Normann, Reframing Business: When the Map Changes the Landscape. John Wiley \& Sons, Inc, 2001.

[31] H. Chesbrough, "Business Model Innovation: Opportunities and Barriers," Long Range Plann., vol. 43, pp. 354-363, 2010.

[32] S. Baytar, Fatma; Ashdown, "An Exploratory Study of Interaction Patterns around the Use of Virtual Apparel Design and Try-on Technology," Fash. Pract. J. Des. Creat. Process Fash., vol. 7, no. 1, pp. 31-52, 2015.

[33] S. Gill, "A review of research and innovation in garment sizing, prototyping and fitting," Text. Prog., vol. 47, no. 1, pp. 1-85, Jan. 2015.

[34] C. Mcdonald, Y. Wu, A. Ballester, and M. Stahl, "IEEE Industry Connections ( IEEE - IC ) Landmarks and Measurement Standards Comparison in 3D Body model Processing," 2018. 